\title{
CARACTERÍSTICAS AGRONÔMICAS E NUTRICIONAIS DO MILHO ADUBADO COM NITROGÊNIO, MOLIBDÊNIO E ZINCO
}

\author{
Alexandre Cunha de Barcellos Ferreira ${ }^{1,3 *}$; Geraldo Antônio de Andrade Araújo²; Paulo Roberto \\ Gomes Pereira²; Antônio Américo Cardoso² \\ ${ }^{1}$ Pós-Graduando do Depto. de Fitotecnia - UFV - Viçosa, MG. \\ ${ }_{3}^{2}$ Depto. de Fitotecnia - UFV, C.P.000 - CEP: 36571-000 - Viçosa, MG. \\ ${ }^{3}$ Bolsista CNPq. \\ *Autor correspondente < acunhabf@prover.com.br >
}

RESUMO: A adubação é um dos fatores que mais contribui para o aumento da produtividade do milho, podendo influenciar a qualidade dos grãos. Este trabalho foi conduzido num Argissolo Vermelho-Amarelo distrófico, visando avaliar os efeitos da adubação com N, Mo e Zn sobre a produção e qualidade de grãos de milho, sob o aspecto protéico e teor de nutrientes minerais; avaliar a época mais adequada para amostragem e análise

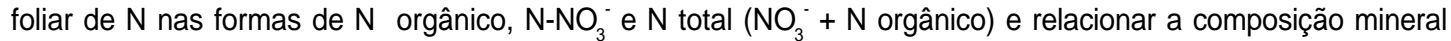
das folhas e dos grãos de milho. Utilizou-se um delineamento em blocos ao acaso com quatro repetições, em esquema fatorial com quatro doses de $\mathrm{N}\left(0,70,140\right.$ e $\left.210 \mathrm{~kg} \mathrm{~h}^{-1}\right)$, duas doses de $\mathrm{Mo}\left(0 \mathrm{e} 90 \mathrm{~g} \mathrm{ha}^{-1}\right)$ e duas de $\left.\mathrm{Zn} \mathrm{(0} \mathrm{e} 3 \mathrm{~kg} \mathrm{ha}^{-1}\right)$. As amostras de folhas foram retiradas aos 25, 45 e aos 63 dae (dias após emergência). No material vegetal obtido (folhas e grãos) foram determinados os teores de $\mathrm{N}$ orgânico, $\mathrm{N}^{-\mathrm{NO}_{3}}$, $\mathrm{N}$ total, proteína, $\mathrm{P}, \mathrm{K}, \mathrm{Ca}, \mathrm{Mg}, \mathrm{S}, \mathrm{Cu}, \mathrm{Fe}, \mathrm{Mn}$, e $\mathrm{Zn}$. O número de espigas por planta, peso das espigas com palha, peso das espigas sem palha, peso de mil grãos e a produção de grãos aumentaram com o incremento nas doses de $\mathrm{N}$, obtendo-se a máxima produção de grãos $\left(8,58 \mathrm{t} \mathrm{ha}^{-1}\right)$ na dose de 201,2 $\mathrm{kg} \mathrm{ha}^{-1}$ de $\mathrm{N}$. Os teores de proteína e nutrientes nos grãos aumentaram com as doses de N. A adubação com Mo elevou o teor de proteína e a com $\mathrm{Zn}$ aumentou o teor desse nutriente nos grãos. Os níveis críticos de $\mathrm{N}$ total foram 2,73 e 2,00 dag kg-1, aos 45 e 63 dae. A melhor característica para ser utilizada como índice de diagnose nutricional e de produção de grãos foi o teor de $\mathrm{N}$ orgânico aos 45 dae (antes do pendoamento), utilizando-se na análise química a última folha completamente aberta. A composição mineral dos grãos, em geral, apresentou alta correlação positiva com a composição mineral das folhas, aos 63 dae.

Palavras-chave: Zea mays, produção de grãos, teor de proteína, teor de minerais, adubação mineral

\section{CORN CROP CHARACTERISTICS UNDER NITROGEN, MOLYBDENUM AND ZINC FERTILIZATION}

\begin{abstract}
Fertilization is the factor that presents the highest contribution to corn yield, and may also affect grain quality. The objective of this work was to evaluate, in a an Ultisol, the fertilization with N, Mo and $\mathrm{Zn}$ on to determine yield and maize grain quality (protein and mineral nutrient contents) and to determine the best sampling time to analyse organic- $\mathrm{N}, \mathrm{NO}^{3-}-\mathrm{N}$ and total- $\mathrm{N}\left(\mathrm{NO}^{3-}-\mathrm{N}+\right.$ organic- $\left.\mathrm{N}\right)$. In addition, nutrient concentrations in maize grain were related to leaves. The experiment was a factorial $4 \times 2 \times 2$ in a randomized complete block design with four replications in which the factors were: four $N$ raes $\left(0,70,140\right.$ and $\left.210 \mathrm{~kg} \mathrm{ha}^{-1}\right)$, two of Mo $(0$ and $\left.90 \mathrm{~g} \mathrm{ha}^{-1}\right)$ and two of $\mathrm{Zn}\left(0\right.$ and $\left.3 \mathrm{~kg} \mathrm{ha}^{-1}\right)$. Leaves were sampled 25, 45 and 63 days after emergency (DAE). Tissue and grain were milled and analysed, and organic- $\mathrm{N}, \mathrm{NO}^{3-}-\mathrm{N}$, total- $\mathrm{N}$, protein, $\mathrm{P}, \mathrm{K}, \mathrm{Ca}, \mathrm{Mg}, \mathrm{S}, \mathrm{Zn}, \mathrm{Fe}, \mathrm{Cu}$ and $\mathrm{Mn}$ contents were evaluated. Zinc and molybdenum applications and their interactions with $\mathrm{N}$ did not affect any yield characteristics. The weight of thousand grains, the number of ears per plant, the weight of ears with and without straw, and yield increased with increased rates. Maximum yield $\left(8.58 \mathrm{t} \mathrm{ha}^{-1}\right)$ was obtained with $201.2 \mathrm{~kg} \mathrm{ha}^{-1} \mathrm{~N}$. Protein content and analysed nutrients in grain increased with increasing $\mathrm{N}$ rate. Mo fertilization raised protein content, while $\mathrm{Zn}$ application increased protein content in grains. The critical levels of total-N were 2.73 and $2.00 \mathrm{dag} \mathrm{kg}^{-1}$ at 45 and $63 \mathrm{DAE}$. The best traits for diagnosis index and yield prediction was the organic- $\mathrm{N}$ content at $45 \mathrm{DAE}$. In general, grain mineral content was positively correlated with leaft mineral content at 63 DAE.
\end{abstract}

Key words: Zea mays, fertilization, protein content, mineral content

\section{INTRODUÇÃO}

É conhecida a importância do nitrogênio quanto às suas funções no metabolismo das plantas, participando como constituinte de moléculas de proteínas, coenzimas, ácidos nucléicos, citocromos, clorofila etc., além de ser um dos nutrientes mais relevantes para o aumento da produção. A adubação nitrogenada influencia não só a produtividade, mas também a qualidade do produto em conseqüência do teor de proteína nos grãos de milho (Sabata \& Mason, 1992; Landry \& Delhaye, 1993; Zhang et al., 1994). O teor de $\mathrm{N}$ nas folhas é muito influenciado pela adubação nitrogenada e, segundo Killorn \& Zourarakis (1992), a concentração foliar de nitrogênio reflete sua 
disponibilidade no solo, sendo que a sua análise pode ser útil na detecção de deficiência de $\mathrm{N}$ e, consequentemente, na predição de produção de grãos.

A aplicação de micronutrientes na cultura do milho na Zona da Mata de Minas Gerais não é comum. A cultura do feijão nesta região tem apresentado expressivos resultados com a aplicação de molibdênio (Vieira et al., 1992; Amane et al., 1994; Berger et al., 1996) , indicando possíveis problemas de deficiência deste elemento. 0 molibdênio exerce papel indispensável na assimilação do nitrato absorvido pelas plantas, atuando a nível da redutase do nitrato. Portanto, qualquer deficiência do elemento pode comprometer o metabolismo do nitrogênio, diminuindo o rendimento das culturas. Quanto ao zinco, é o micronutriente mais limitante à produção da cultura do milho e o que geralmente apresenta maiores problemas de deficiência nos solos brasileiros (Ritchey et al., 1986). O maior crescimento de plantas de milho, promovido pela aplicação de doses elevadas de $\mathrm{N}$, resulta em diluição de Zn na planta, provocando sua deficiência e necessidade de seu uso na adubação (Floneragan \& Webb, 1993).

A concentração de determinado nutriente pode indicar o estado nutricional da planta, pois existe relação básica entre essa concentração e o crescimento ou produtividade da cultura (Bataglia, 1991). Nesta região, entretanto, não se tem dado as devidas atenções para a diagnose foliar na avaliação direta do estado nutricional da cultura do milho.

Assim, este trabalho tem por objetivo verificar os efeitos da adubação com N, Mo, Zn e suas interações sobre a produção e qualidade de grãos de milho, sob o aspecto protéico e teor de nutrientes; avaliar a época mais adequada de amostragem para o diagnóstico nutricional nitrogenado da cultura e estudar a relação entre as concentrações dos nutrientes $\mathrm{N}$ total, $\mathrm{P}, \mathrm{S}, \mathrm{Ca}, \mathrm{Mg}, \mathrm{K}, \mathrm{Zn}$, $\mathrm{Cu}, \mathrm{Fe}$ e $\mathrm{Mn}$ nas folhas e nos grãos.

\section{MATERIAL E MÉTODOS}

O estudo foi conduzido na Estação Experimental da UFV, Coimbra-MG, em solo Argissolo VermelhoAmarelo distrófico. Anteriormente à instalação do experimento, foram coletadas amostras de solo à profundidade de $0-20 \mathrm{~cm}$, para caracterizações físicas e químicas. As análises indicaram $17,5 \mathrm{~g} \mathrm{~kg}^{-1}$ de carbono orgânico; pH 5,60 (1:2,5) em água; $5,80 \mathrm{mg} \mathrm{dm}^{-3}$ de P; $18 \mathrm{mg} \mathrm{dm}^{-3}$ de $\mathrm{K} ; 0 \mathrm{mmol}_{\mathrm{c}} \mathrm{dm}^{-3}$ de $\mathrm{Al}^{3+}$ trocável; 19 $\mathrm{mmol}_{\mathrm{c}} \mathrm{dm}^{-3}$ de $\mathrm{Ca}^{2+} ; 6 \mathrm{mmol}_{\mathrm{c}} \mathrm{dm}^{-3}$ de $\mathrm{Mg}^{2+} ; 0,713 \mathrm{mmol}_{\mathrm{c}}$ $\mathrm{dm}^{-3}$ de $\mathrm{Zn}^{2+} ; 240 \mathrm{~g} \mathrm{~kg}^{-1}$ de areia; $180 \mathrm{~g} \mathrm{~kg}^{-1}$ de silte e $580 \mathrm{~g} \mathrm{~kg}^{-1}$ de argila.

Foi utilizado o delineamento em blocos ao acaso com quatro repetições, em esquema fatorial com quatro doses de $\mathrm{N}\left(0,70,140\right.$ e $\left.210 \mathrm{~kg} \mathrm{ha}^{-1}\right)$, duas doses de Mo $\left(0\right.$ e $\left.90 \mathrm{~g} \mathrm{ha}^{-1}\right)$ e duas de $\mathrm{Zn}\left(0\right.$ e $\left.3 \mathrm{~kg} \mathrm{ha}^{-1}\right)$, totalizando 64 parcelas. Cada parcela foi constituída de cinco linhas medindo $7 \mathrm{~m}$ de comprimento cada uma, distanciadas em $1 \mathrm{~m}$. A parcela útil com $15 \mathrm{~m}^{2}$ foi formada de três linhas centrais, excluindo-se, como bordadura, as linhas externas e $1 \mathrm{~m}$ de cada cabeceira. Como adubação básica, todos os tratamentos receberam no sulco de plantio $52 \mathrm{~kg} \mathrm{ha}^{-1}$ de $\mathrm{P}$, na forma de superfosfato simples e $50 \mathrm{~kg} \mathrm{ha}^{-1}$ de $\mathrm{K}$, como cloreto de potássio. $\mathrm{O} \mathrm{Zn}$ foi aplicado no sulco de plantio na forma de sulfato de zinco e o Mo como molibdato de sódio por via foliar, aos 45 dias após a emergência (dae), nos respectivos tratamentos. $O$ adubo nitrogenado, na forma de sulfato de amônio, foi aplicado parceladamente, sendo $10 \mathrm{~kg} \mathrm{ha}^{-1}$ na semeadura e o resto dividido em doses equivalentes a 40 e $60 \%$, aplicado aos 25 e 45 dae, respectivamente. Semeou-se o milho híbrido precoce AG 612, na população de 50.000 plantas por hectare, no mês de novembro de 1994.

Das 3 linhas centrais (parcela útil), somente uma linha foi utilizada na coleta de folhas para análise, nos períodos correspondentes aos estádios fisiológicos indicados por Jones Jr. et al. (1991). Aos 25 dae, quando as plantas apresentavam aproximadamente 3 pares de folhas, foi coletada a parte aérea de 3 plantas por unidade experimental. Aos 45 dae, antes do pendoamento, foi coletada a última folha completamente aberta de 3 plantas e aos 63 dae, no início do embonecamento, a folha da primeira espiga, também, em 3 plantas.

A colheita das espigas foi realizada após todas as parcelas estarem completamente secas. Os grãos foram retirados para análise, de cada parcela, após a colheita e avaliação dos componentes de produção.

Os tecidos vegetais coletados e os grãos foram secos em estufa com ventilação forçada a $70^{\circ} \mathrm{C}$ até atingirem peso constante e depois moídos. As folhas foram moídas inteiras, incluindo a nervura central. $\mathrm{O}$ teor de $\mathrm{N}$ orgânico no extrato, obtido por digestão sulfúrica, foi dosado usando-se o reagente de Nessler (Jackson, 1958). $\mathrm{O}$ teor de $\mathrm{N}-\mathrm{NO}_{3}$ foi determinado conforme metodologia descrita por Cataldo et al. (1975). O N total foi calculado pela soma dos teores de $\mathrm{NO}_{3}^{-}$e $\mathrm{N}$ orgânico. Os teores de proteína foram obtidos pela multiplicação dos teores de $\mathrm{N}$ orgânico pelo fator 6,25 (Watt \& Merril, 1975).

Após a digestão nítrico-perclórica, determinaramse os teores de $\mathrm{K}$ por fotometria de chama; $\mathrm{Ca}, \mathrm{Mg}$, $\mathrm{Fe}$, $\mathrm{Zn}$, Cu e Mn por espectrometria de absorção atômica, $\mathrm{P}$ por colorimetria pelo método da vitamina $C$, com espectrofotômetro (Braga \& Defelipo, 1974) e S por turbidimetria com sulfato de bário (Blanchar et al., 1965).

Os efeitos dos tratamentos sobre 0 desenvolvimento da cultura de milho foram avaliados pelas variáveis altura das plantas, número de plantas por parcela, número de plantas acamadas por parcela, número de plantas quebradas por parcela, número de espigas por planta, peso das espigas com palha, peso das espigas sem palha, peso de mil grãos e a produção de grãos, corrigidos para $14 \%$ de umidade.

Os resultados foram submetidos à análises de variância e ajuste de equações de regressão. Na seleção das equações de regressão, as significâncias dos coeficientes dos modelos foram considerados pelo teste t, a $5 \%$. 
Para se avaliar a relação entre a composição química das folhas e dos grãos efetuou-se a correlação linear simples de Pearson, entre os teores $\mathrm{N}$ orgânico, $\mathrm{N}$ $\mathrm{NO}_{3}$ e $\mathrm{N}$ total, quantificados nas três épocas de amostragem, com a produção de grãos. Análises de correlação também foram realizadas para os teores de proteína nos grãos com o $\mathrm{N}$ orgânico foliar aos 63 dae, e para os teores de $\mathrm{P}, \mathrm{K}, \mathrm{S}, \mathrm{Ca}, \mathrm{Mg}, \mathrm{Zn}, \mathrm{Fe}, \mathrm{Cu}$ e $\mathrm{Mn}$ nos grãos com seus respectivos teores nas folhas aos 63 dae. As significâncias dos coeficientes de correlação foram consideradas até $5 \%$.

Estimaram-se as concentrações de nutrientes com a dose de $\mathrm{N}$ que proporcionou $90 \%$ da produção máxima, por meio das equações que relacionavam as concentrações foliares com as doses de $\mathrm{N}$ aplicadas. Nos casos em que não houve efeito significativo dos tratamentos, os teores foram considerados pela média dos tratamentos.

\section{RESULTADOS E DISCUSSÃO}

\section{Desenvolvimento da cultura de milho}

As características altura da planta, número de plantas por parcela, número de plantas acamadas e quebradas não foram afetadas $(P \leq 0,05)$ pela adubação nitrogenada, atingindo valores médios de $2,38 \mathrm{~m}$; 48 plantas por parcela; 0,63 plantas por parcela $(1,3 \%)$ e 4,88 plantas por parcela $(10,17 \%)$, respectivamente.

A produção de grãos, o peso das espigas com e sem palha (Figura 1), o peso de mil grãos (Figura 2) e 0 número de espigas por planta (Figura 3 ) foram positivamente e $(P \leq 0,01)$ influenciados pelo incremento nas doses de N. Nenhuma das características acima descritas foi influenciada pela aplicação de $\mathrm{Zn}$, Mo e suas interações com o N. Alguns trabalhos têm mostrado respostas positivas à aplicação de zinco na cultura do milho (Ritchey et al., 1986; Galrão, 1994), devido à sua atuação na produção de triptofano, precursor do ácido indol acético, fitohormônio promotor do crescimento. Quanto a produção, a ausência de resposta significativa do milho

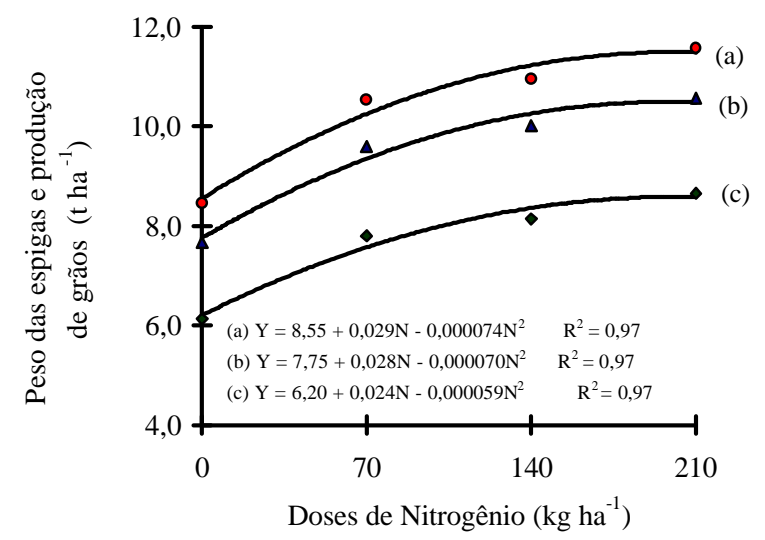

Figura 1 - Efeito das doses de nitrogênio sobre o peso das espigas com palha (a), sem palha (b) e produção de grãos (c). à aplicação de $\mathrm{Zn}$ pode ter ocorrido devido à alta disponibilidade de zinco no solo $\left(23,3 \mathrm{mg} \mathrm{dm}^{-3}\right)$. Este valor está bem acima do nível crítico encontrado por Couto et al. (1992) usando extrator Mehlich-1, em solos com diferentes valores do fator capacidade $(0,8$ a 4,6 $\mathrm{mg} \mathrm{dm}^{-3}$ ) para cultura de milho.

A ausência de resposta da adubação com molibdênio pode ser devida ao teor deste nutriente no solo, suposto suficiente. Outra explicação para este fato seria a reserva de Mo nas sementes, pois, segundo Weir \& Hudson, citados por Tanner (1982), o teor de 0,08 $\mathrm{mg} \mathrm{kg}^{-1}$ de Mo nas sementes de milho é suficiente para possibilitar o crescimento e desenvolvimento normal das plantas. Essa ausência de resposta poderia ser também devido à época de aplicação que, neste trabalho, foi aos 45 dias após a emergência, época talvez tardia para correção de possíveis deficiências. A literatura demonstra que a melhor época de aplicação de Mo, via foliar, é aos 15 dias após a emergência (Araújo et al., 1996).

As doses de nitrogênio que proporcionaram valores máximos no peso das espigas com palha (11,48 $\mathrm{t}$ $\left.\mathrm{ha}^{-1}\right)$, no peso das espigas sem palha $\left(10,48 \mathrm{t} \mathrm{ha}^{-1}\right)$ e na produção de grãos $\left(8,58 \mathrm{t} \mathrm{ha}^{-1}\right)$ foram 199,$6 ; 197,0 \mathrm{e}$ $201,2 \mathrm{~kg} \mathrm{ha}^{-1}$, respectivamente (Figura 1).

A produtividade de grãos dos tratamentos que não receberam $\mathrm{N}$ foi de $6204 \mathrm{~kg} \mathrm{ha}^{-1}$, atingindo produtividade bem acima da média nacional, que é 2350 $\mathrm{kg} \mathrm{ha}^{-1}$ (EMATER, 1996), evidenciando que esse solo possui capacidade relativamente satisfatória de suprimento de N. A produção de grãos apresentou incremento de 38,3 $\%$ com o aumento da dose de 0 para 201,2 $\mathrm{kg} \mathrm{ha}^{-1}$ de nitrogênio.

O aumento do peso de mil grãos (Figura 2) em função do incremento nas doses de $\mathrm{N}$ pode ter sido determinado principalmente pelas diferenças no período efetivo de enchimento dos grãos, à semelhança dos obtidos por Lemcoff \& Loomis (1986) e Wolfe et al. (1988). No presente trabalho, aos 120 dias após a emergência, observou-se, nas parcelas que não receberam o $\mathrm{N} \mathrm{ou}$ naquelas com doses mais baixas, que as folhas inferiores e a palha da espiga apresentavam-se bem secas

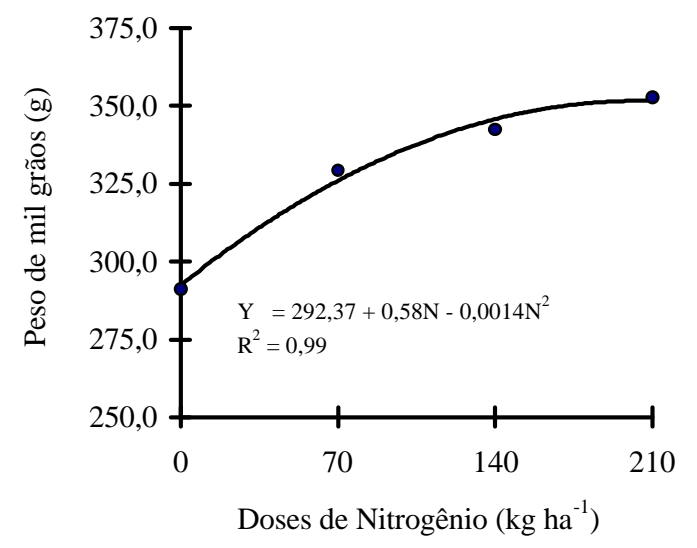

Figura 2 - Peso de mil grãos em função de doses de nitrogênio. 
enquanto, nas parcelas com maior dosagem de $\mathrm{N}$, as plantas estavam bem mais verdes, prolongando o período de retranslocação de açúcares e $\mathrm{N}$ para os grãos e aumentando o peso final.

O número de espigas por planta aumentou com o incremento da adubação nitrogenada, sendo sua melhor representação alcançada pela curva de resposta de efeito quadrático $\left(Y=1,06+0,0015 \mathrm{~N}-0,0000045 \mathrm{~N}^{2} R^{2}=0,99\right)$. A formação da segunda espiga, em algumas plantas, contribuiu para o aumento da produtividade.

\section{Nutrição da cultura do milho}

Os teores de todos os nutrientes analisados nos grãos aumentaram significativamente com a adubação nitrogenada, enquanto que a adubação molíbdica aumentou em $3 \%$ o teor de proteína dos grãos (significativo a $5 \%$ pelo teste $\mathrm{F}$ ). Essa influência positiva do molibdênio sobre o teor de proteína pode ser atribuída à sua atuação no metabolismo do nitrogênio, através do aumento da atividade da redutase do nitrato. Essa enzima catalisa a redução biológica do nitrato a nitrito, sendo este o primeiro passo para a incorporação do $\mathrm{N}$ em proteínas (Marschner, 1995).

O teor de zinco nos grãos aumentou em 6,6 \% (diferença significativa pelo teste $\mathrm{F}$ a $1 \%$, devido à sua aplicação no sulco de plantio, à semelhança do obtido por Csathó \& Lasztity (1994). O maior teor de Zn observado no presente trabalho deve estar relacionado à sua maior absorção com sua aplicação, sendo armazenado nas partes vegetativas e com posterior translocação para os grãos. Aos 25 dae o teor foliar de zinco aumentou, em relação à testemunha, de 24 para $41,5 \mathrm{mg} \mathrm{kg}^{-1}$; aos 45 dae de 17,5 para $21,3 \mathrm{mg} \mathrm{kg}^{-1}$ e aos 63 dae de 19,3 para $24,5 \mathrm{mg} \mathrm{kg}^{-1}$. Estes incrementos, entretanto, conforme já destacado, não resultaram em ganho de produtividade, provavelmente devido ao alto nível de zinco no solo.

Para as doses de $\mathrm{N}$ aplicadas, entre 0 e 210 $\mathrm{kg} \mathrm{ha}^{-1}$, o teor de proteína no grão (Figura 3a) passou de 7,5 para 10,5 dag $\mathrm{kg}^{-1}$. Resultados semelhantes foram obtidos por Zhang et al. (1993) e Ahmadi et al. (1995). O nitrogênio absorvido pelas plantas combina com esqueletos carbônicos para a produção de aminoácidos, os quais resultam em proteínas que ficam armazenadas nos tecidos vegetais. Por ocasião da fase de enchimento de grãos estas reservas são quebradas, translocadas e armazenadas nestes órgãos, na forma de proteínas e aminoácidos (Marschner, 1995).

$\mathrm{O}$ incremento nas doses de $\mathrm{N}$ aumentou o teor de enxofre (S) nos grãos (Figura 3b). É importante ressaltar que a disponibilidade de $S$ no solo foi aumentada pela utilização do sulfato de amônio como fonte de N.

Os teores de fósforo $(\mathrm{P})$ e potássio (K) (Figura $3 \mathrm{c}$ ) aumentaram com a adubação nitrogenada, resultados estes também encontrados por Thiraporn et al. (1992). Estes autores observaram que a partição de $P$ para os grãos aumentou com a aplicação de N, ou seja, a taxa de translocação de $\mathrm{P}$ para os grãos depende do nível de fornecimento de $\mathrm{N}$ para a planta. Carle's et al., citado por Arnon (1975), verificaram que $90 \%$ do $P$ acumulado na parte vegetativa foram para os grãos, em plantas de milho supridas adequadamente com $\mathrm{N}$, enquanto em plantas deficientes a translocação foi de $40 \%$.

Quanto ao K, como o aumento da produção de grãos está diretamente relacionado com o maior transporte e armazenamento de fotoassimilados nos grãos, o seu teor tende também a aumentar, pois ele participa do transporte de sacarose e fotoassimilados no sentido da fonte para 0 dreno (Marschner, 1995).

Foram também encontradas respostas positivas à aplicação de nitrogênio em relação aos teores de cálcio (Figura 3d), magnésio (Figura 3e) e zinco (Figura 3f). Mesmo sendo praticamente imóvel no floema e translocando-se muito pouco para os grãos, o cálcio teve seu teor aumentado com as doses de nitrogênio. Esta resposta provavelmente pode estar relacionada à maior necessidade de cálcio nos grãos para formação de parede celular, de tal modo que possa suportar a maior quantidade de metabólitos translocados aos grãos com a adubação nitrogenada.

O zinco é um micronutriente de mobilidade intermediária no floema e sua maior ou menor translocação depende de sua disponibilidade na parte vegetativa pois, quando em maiores concentrações, apresenta-se complexado a compostos orgânicos de baixo peso molecular (Marschner, 1995). Pelos resultados de análise foliar, quanto maior a dose de $\mathrm{N}$ aplicada, maior foi a concentração de zinco. Segundo Jurkowska et al. (1990), quanto maior o teor deste micronutriente no tecido vegetativo, maior é a translocação e acúmulo nos grãos.

A interação nitrogênio $x$ molibdênio apresentou efeito sobre o teor de Fe. No desdobramento da interação, obteve-se resposta quadrática à aplicação de $\mathrm{N}$ na ausência de Mo e aumento linear do teor de $\mathrm{Fe}$ na presença de Mo (Figura $3 \mathrm{~g}$ ). Na ausência de N, o efeito do Mo sobre o teor de Fe foi evidente, elevando-o em 121 $\%$ quando comparado à ausência de Mo. Este incremento pode estar relacionado à participação do Mo no metabolismo do Fe (Inden, citado por Gupta \& Lipsett, 1981), atuando em sua absorção e transporte (Rains, citado por Malavolta et al.,1991). Outra explicação seria que a essencialidade do Mo no metabolismo do N, propiciaria maior formação de clorofila, na qual existe a participação do ferro (Marschner, 1995).

Os teores de $\mathrm{Cu}$ e $\mathrm{Mn}$ mostraram relação linear crescente em função das doses de nitrogênio (Figura 3h). Isso pode estar relacionado à maior absorção e translocação dos micronutrientes devido à adubação nitrogenada, a qual pode causar acidificação da rizosfera, provocada pela nitrificação ou absorção do íon amônio. A acidificação do solo aumenta a disponibilidade dos micronutrientes $\mathrm{Cu}, \mathrm{Mn}$, Fe e Zn (Moraghan \& Mascagni Jr., 1991). 

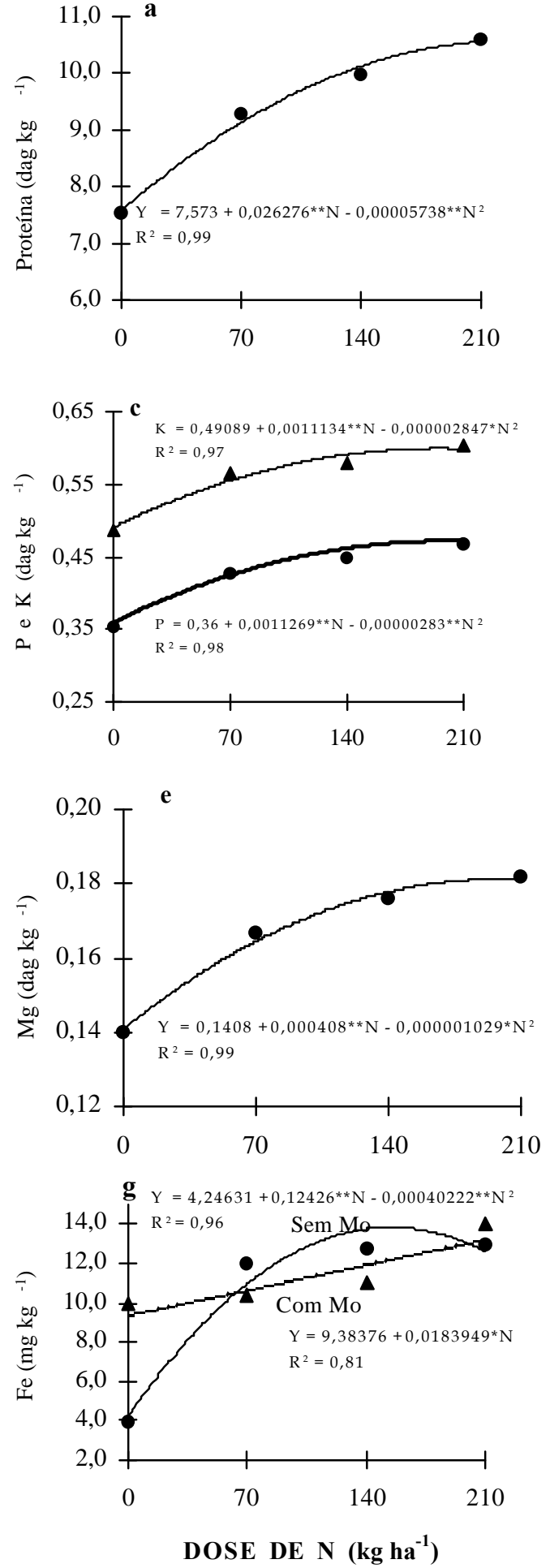
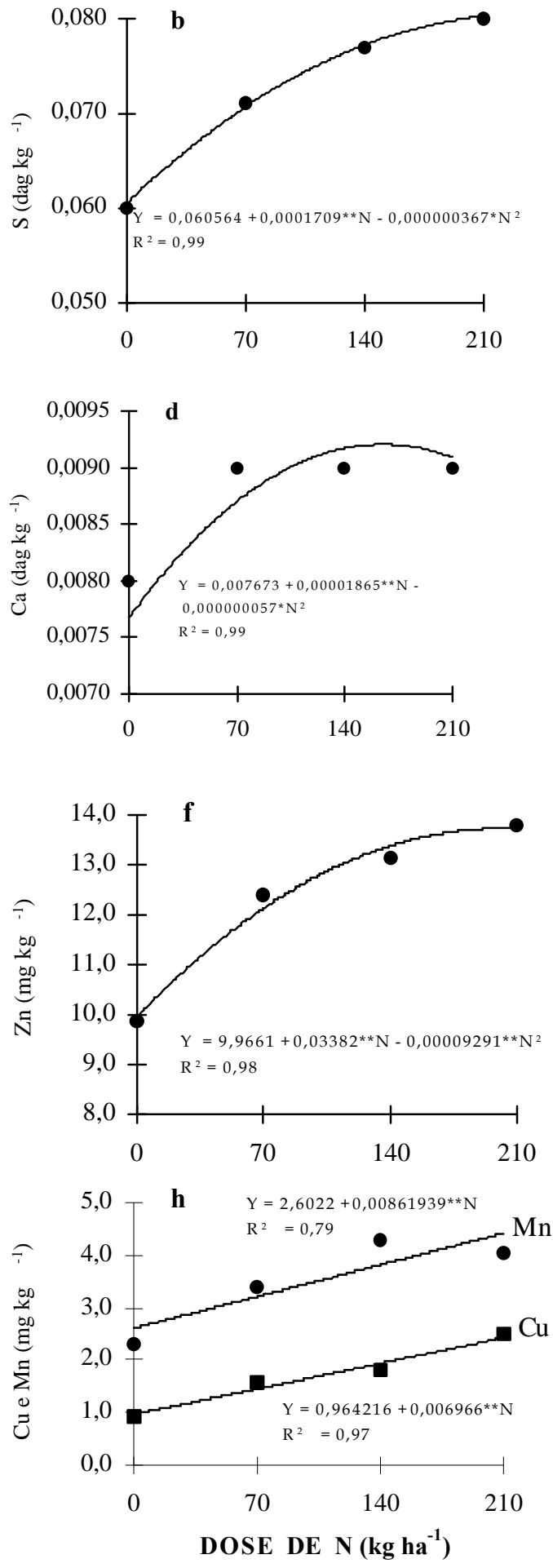

Figura 3 - Teores nos grãos de proteína (a), enxofre (b), fósforo e potássio (c), cálcio (d), magnésio (e), zinco (f), ferro (g), cobre e manganês $(h)$, em função de doses de nitrogênio, na forma de sulfato de amônio.

A dose $198 \mathrm{~kg} \mathrm{ha}^{-1}$ de nitrogênio propiciou as concentrações máximas dos teores de $\mathrm{P}, \mathrm{K}, \mathrm{Mg}$ e $Z n$, sendo que a concentração máxima de $\mathrm{Ca}$ foi obtida com $167 \mathrm{~kg} \mathrm{ha}^{-1}$. Para os teores de proteína e enxofre, os pontos de máximo estiveram acima das doses de nitrogênio utilizadas.
Com o aumento das doses de nitrogênio observaram-se, nos grãos, ganhos expressivos nos teores de proteína $(39,1 \%) ; \mathrm{S}(33,3 \%) ; \mathrm{P}$ $(31,1 \%) ; \mathrm{K}(22,2 \%)$; Ca $(12,5 \%) ; \mathrm{Mg}(28,4 \%)$; $\mathrm{Zn}(30,6 \%) ; \mathrm{Cu}(144,5 \%) ; \mathrm{Mn}(66,4 \%)$ e $\mathrm{Fe}$ $(206,4 \%)$. 


\section{Relação nutricional entre folha e grãos na cultura do milho}

Os teores foliares de $\mathrm{N}$ orgânico, $\mathrm{N}-\mathrm{NO}_{3}$ e $\mathrm{N}$ total quantificados aos 25 dae apresentaram coeficientes de correlação linear não significativos com a produção de grãos, não sendo boas características preditivas da produtividade de grãos (TABELA 1). Segundo Ta \& Weiland (1992), o N absorvido nos estádios iniciais apresenta principalmente função no sistema estrutural na planta, sendo, portanto, pouco armazenado e translocado. Binford et al. (1992) verificaram que a concentração de N nas plantas jovens tem relativamente pouco efeito sobre a produção final, não sendo um indicador confiável da disponibilidade de $\mathrm{N}$ nas plantas de milho.

Aos 45 e 63 dae, os teores de $N$ orgânico apresentaram altos coeficientes de correlação com a produção evidenciando, portanto, ser uma variável com promissora capacidade preditiva do nível de colheita. $\mathrm{O}$ mesmo ocorreu com os teores de $\mathrm{N}$ total nessas duas épocas de amostragem e de $\mathrm{N}-\mathrm{NO}_{3}$ aos 45 dae, apesar deste último somente ser significativo a $5 \%$ de probabilidade.

Embora os teores de $\mathrm{N}$ orgânico e $\mathrm{N}$ total na $3^{\text {a }}$ amostragem apresentassem elevados coeficientes de correlação com a produção, eles não devem ser utilizados, uma vez que não haveria tempo suficiente para correção da deficiência de nitrogênio em plantas de milho, porque após o florescimento a absorção, assimilação e translocação do $\mathrm{N}$ para a parte aérea é baixa, os tecidos vegetais iniciam o processo de senescência e os grãos em formação passam a ser o dreno principal (Arnon, 1975).

A existência de correlações entre os teores de $\mathrm{N}$ orgânico e $\mathrm{N}$ total aos 45 dae com a produção de grãos, indica a importância destas características nas avaliações do estado nutricional nitrogenado do milho, podendo ser utilizados como meio para detectar deficiências e predizer respostas. Porém, o procedimento analítico para

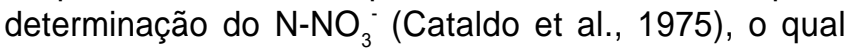
integra o $\mathrm{N}$ total é muito trabalhoso, inviabilizando-o como rotina, devendo-se optar somente pelo teor de $\mathrm{N}$ orgânico.

O teor foliar de $\mathrm{N}$ orgânico aos 63 dae apresentou coeficiente de correlação linear positivo $\left(r=0,91^{\star * *}\right)$ com o teor de proteína dos grãos, evidenciando a importância

TABELA 1 - Coeficientes de correlação linear entre as médias da variável produção de grãos com as médias das variáveis $\mathrm{N}$ orgânico, $\mathrm{N}-\mathrm{NO}_{3}^{-}$e $\mathrm{N}$ total, nas três épocas de amostragem.

\begin{tabular}{|c|c|c|c|}
\hline \multirow[t]{2}{*}{ Variável } & \multicolumn{3}{|c|}{ Dias após a emergência } \\
\hline & 25 & 45 & 63 \\
\hline $\mathrm{N}$ orgânico & $-0,21^{\text {ns }}$ & $0,85^{* * *}$ & $0,83^{* * *}$ \\
\hline $\mathrm{N}-\mathrm{NO}_{3}-$ & $0,18^{\text {ns }}$ & $0,57^{*}$ & $-0,21^{\text {ns }}$ \\
\hline $\mathrm{N}$ total & $-0,15^{\mathrm{ns}}$ & $0,85^{\star * *}$ & $0,83^{* * *}$ \\
\hline
\end{tabular}

do nível nutricional de $\mathrm{N}$ na síntese protéica, conforme também verificado por Zhang et al. (1994). Também foram observados coeficientes de correlação linear positivos entre os teores de $P\left(r=0,81^{* * *}\right)$, $S\left(r=0,8^{* * *}\right)$, $\mathrm{Ca}(r=$ $\left.0,48^{\star}\right)$, Zn $\left(r=0,59^{* * *}\right), \mathrm{Cu}\left(r=0,85^{\star * *}\right)$ e $\mathrm{Mn}\left(r=0,55^{\star}\right)$ nos tecidos foliares e, respectivos teores, nos grãos. $A$ existência de coeficientes de correlação não-significativo entre os teores foliares de $\mathrm{Mg}\left(r=0,23^{\mathrm{ns}}\right), \mathrm{K}\left(r=-0.34^{\mathrm{ns}}\right)$ e Fe $\left(r=0,38{ }^{\text {ns }}\right)$ com seus respectivos teores nos grãos sugere que a translocação desses nutrientes armazenados nos tecidos vegetativos até os 63 dae não foi determinante para elevação de seus teores nos grãos. Provavelmente, este efeito foi proporcionado principalmente pela maior absorção desses nutrientes do solo e a mobilização para os grãos durante o estádio reprodutivo, ou porque a translocação ocorreu principalmente a partir de outras folhas que não a amostrada.

Os resultados de correlação linear positiva da composição química da folha com a composição dos grãos reforçam a explicação do acúmulo de proteína (Figura 3a) e nutrientes nos grãos (Figuras $3 b, c, d, f, h$ ) em função da elevação nas doses de N, uma vez que os nutrientes armazenados nas partes vegetativas são posteriormente retranslocados para os grãos durante a fase de enchimento (Marschner, 1995).

\section{Níveis críticos dos nutrientes}

A partir das equações de regressão (TABELA 2) desenvolvidas em função das doses de aplicação de nitrogênio, foram estimados os teores dos nutrientes na folha da cultura de milho aos 45 e 63 dae, necessários para garantir $90 \%$ da produção máxima de grãos (TABELA 3). Como não houve efeito significativo das doses de $\mathrm{N}$ sobre os teores de $\mathrm{P}, \mathrm{Ca}, \mathrm{Mg}, \mathrm{Fe}, \mathrm{Cu}$ e $\mathrm{Mn}$ aos 45 dae, e de $\mathrm{K}, \mathrm{Ca}$ e $\mathrm{Mg}$ aos 63 dae, estes foram considerados com base nos valores médios observados.

\section{TABELA 2 - Equações de regressão ajustadas para os teo- res de nutrientes na folha da cultura de milho, aos 45 e 63 dias após a emergência ( $2^{\mathrm{a}}$ e $3^{\mathrm{a}}$ amostragem, respectivamente), em função das doses de nitrogênio $\left(\mathrm{kg} \mathrm{ha}^{-1}\right)$.}

\begin{tabular}{|c|c|}
\hline $\begin{array}{c}\text { Relação entre o teor na } \\
\text { folha e a dose de } \mathrm{N}\end{array}$ & $\begin{array}{c}\text { Coeficiente de } \\
\text { determinação }\left(R^{2}\right)\end{array}$ \\
\hline \multicolumn{2}{|l|}{ Segunda amostragem } \\
\hline $\mathrm{N}$ total $=2,51+0,0028^{*} \cdot \mathrm{N}$ & 0,87 \\
\hline$S=0,13+0,0001^{* \star} . N$ & 0,88 \\
\hline$K=1,85-0,0013^{* *} . N$ & 0,91 \\
\hline \multicolumn{2}{|l|}{ Terceira amostragem } \\
\hline $\mathrm{N}$ total $=1,8+0,0025^{* *} . \mathrm{N}$ & 0,87 \\
\hline$P=0,18-0,0002^{* *} . N$ & 0,98 \\
\hline $\mathrm{Cu}=9,23+0,0168^{* *} \cdot \mathrm{N}$ & 0,86 \\
\hline$S=0,087+0,00025^{\star *} . N$ & 0,94 \\
\hline $\mathrm{Fe}=95,28+0,0845^{\star *} \cdot \mathrm{N}$ & 0,57 \\
\hline $\mathrm{Zn}=17,85+0,0298^{\star *} \cdot \mathrm{N}$ & 0,51 \\
\hline$M n=68,36+0,678^{*} \cdot N-0,0025^{\star} \cdot N^{2}$ & 0,75 \\
\hline
\end{tabular}


TABELA 3 - Níveis críticos de $\mathrm{N}$ e teores dos nutrientes nas folhas da cultura de milho, aos 45 e 63 dias após a emergência (dae), para se obter $90 \%$ da produção máxima de grãos, obtidos em função das doses de nitrogênio.

\begin{tabular}{|c|c|c|c|c|}
\hline Nutrientes & 45 dae & Suficiente ${ }^{\star *}$ & 63 dae & Suficiente ${ }^{\star \star}$ \\
\hline $\mathrm{N}$-total ${ }^{1 /}$ & $2,73^{\square}$ & $3,00-3,50$ & $2,00 \square$ & $2,70-4,00$ \\
\hline$S^{1 /}$ & $0,14^{\square}$ & $0,15-0,50$ & $0,11^{\square}$ & $0,21-0,50$ \\
\hline$P^{1 /}$ & 0,21 * & $0,25-0,45$ & $0,16^{\square}$ & $0,25-0,50$ \\
\hline $\mathrm{K}^{1 /}$ & $1,74^{\square}$ & $2,00-2,50$ & 1,33 * & $1,70-3,00$ \\
\hline $\mathrm{Ca}{ }^{1 /}$ & 0,58 * & $0,25-0,50$ & 0,60 * & $0,21-1,00$ \\
\hline$M g^{1 /}$ & 0,39 * & $0,13-0,30$ & $0,37^{*}$ & $0,20-1,00$ \\
\hline $\mathrm{Zn}^{21}$ & $18,18-21,45^{\Delta}$ & $15-60$ & $18,16-23,45^{\Delta}$ & $25-100$ \\
\hline $\mathrm{Cu}^{2 /}$ & 13,02 * & $3-15$ & $10,57^{\square}$ & $6-20$ \\
\hline $\mathrm{Fe}^{21}$ & 164,90 * & $10-20$ & $95,67-116,17^{\Delta}$ & $21-250$ \\
\hline $\mathrm{Mn}{ }^{21}$ & 110,48 * & $15-300$ & $106,53^{\square}$ & $20-200$ \\
\hline
\end{tabular}

${ }^{1 /} \mathrm{e}^{2 /}$ - dag $\mathrm{kg}^{-1}$ e $\mathrm{mg} \mathrm{kg}^{-1}$, respectivamente

* - Teores médios observados

$\Delta$ - amplitude de variação entre o menor e o maior teor médio observado

$\square$ - Teores estimados

** - Teores considerados suficientes por Jones Jr. et al. (1991).

O teor de zinco, aos 45 dae, foi considerado pela amplitude de variação entre o menor e o maior teor médio observado, em função da dose de N. Amplitude de variação semelhante foi utilizada nos teores de Fe e $\mathrm{Zn}$, aos 63 dae, pois os coeficientes de determinação das equações de regressão foram baixos.

Os teores médios observados de $\mathrm{N}$ orgânico aos 45 e 63 dae foram 2,68 e 2,03 dag kg ${ }^{-1}$, enquanto os de $\mathrm{N}-\mathrm{NO}_{3}$ foram 0,13 e 0,031 dag kg ${ }^{-1}$, respectivamente.

Os níveis críticos de $\mathrm{N}$ necessários para a obtenção de $90 \%$ do rendimento máximo de grãos foram 2,73 e 2,00 dag kg-1, respectivamente aos 45 e 63 dae. 0 nível crítico de $\mathrm{N}$ aos 63 dae foi menor que o encontrado por Melsted et al. (1969) (3,00 dag $\left.\mathrm{kg}^{-1}\right)$, podendo ser atribuído às diferenças ambientais e genéticas, as quais influenciam a absorção, translocação e acúmulo de nutrientes, síntese de fotoassimilados e a produção de grãos.

\section{CONCLUSÕES}

- A produção foi positivamente influenciada pela adubação nitrogenada e, entre seus componentes, o número de espigas por planta, o peso das espigas com e sem palha e o peso de mil grãos aumentaram de forma quadrática com o incremento das doses do adubo nitrogenado.

- A adubação nitrogenada melhorou a qualidade dos grãos de milho, em conseqüência do aumento nos teores de protéina e dos nutrientes minerais $\mathrm{P}, \mathrm{K}, \mathrm{Ca}, \mathrm{Mg}$, $\mathrm{S}, \mathrm{Cu}, \mathrm{Fe}, \mathrm{Mn}$ e Zn.

- O molibdênio aumentou o teor de proteína e a aplicação de Zn elevou seu teor nos grãos.

- A melhor característica para ser utilizada como índice de diagnóstico e predição de produção de grãos foi o teor de $\mathrm{N}$ orgânico aos 45 dae (antes do pendoamento), utilizando-se a última folha completamente aberta.
- A composição mineral dos grãos apresentou, em geral, alta correlação positiva com a composição mineral foliar, aos 63 dae.

\section{REFERÊNCIAS BIBLIOGRÁFICAS}

AHMADI, M.; WIEBOLD, W.J.; BEUERLEIN, J.E.; KEPHART, K.D. Protein quality of corn hybrids differing for endosperm characteristics and the effect of nitrogen fertilization. Journal of Plant Nutrition, v.18, p.1471-1481, 1995.

AMANE, M.I.V.; VIEIRA, C.; CARDOSO. A.A.; ARAÚJO, G.A. de A. Resposta de cultivares de feijão (Phaseolus vulgaris L.) às adubações nitrogenada e molíbdica. Revista Ceres, v.41, p.202-216, 1994

ARAÚJO, G.A. de A.; VIEIRA, C.; BERGER, P.G.; GALVÃO, J.C.C. Épocas de aplicação de molibdênio na cultura do milho. In: CONGRESSO NACIONAL DE MILHO E SORGO, 21. Londrina, 1996. Anais. Londrina: IAPAR, 1996. p.160.

ARNON, I. Mineral nutrition of maize. Bern: International Potash Institute, 1975. 452p.

BATAGLIA, O.C. Análise química de plantas. In: FERREIRA, M.E.; CRUZ, M.C.P. (Ed.) Micronutrientes na agricultura. Piracicaba: Associação Brasileira para a Pesquisa da Potassa e do Fosfato, 1991. p.289-308.

BERGER, P.G.; VIEIRA, C.; ARAÚJO, G.A. de A. Efeitos de doses e épocas de aplicação de molibdênio sobre a cultura do feijão. Pesquisa Agropecuária Brasileira, v.31, p.473-480, 1996.

BINFORD, G.D.; BLACKMER, A.M.; CERRATO, M.E. Nitrogen concentration of young corn plants as an indicator of nitrogen availability. Agronomy Journal, v.84, p.219-223, 1992.

BLANCHAR, R.W.; REHM, G.; CALDWELL, A.C. Sulfur in plant material by digestion with nitric and perchloric acid. Soil Science Society of America Proceedings, v.29, p.71-72, 1965.

BRAGA, J.M.; DEFELIPO, B.V. Determinação espectofotométrica de fósforo em extratos de solos e plantas. Revista Ceres, v.21, p.73-85, 1974.

CATALDO, D.A.; HAROON, M.; SCHARDER, M.; YOUNGS, V.L. Rapid colorimetric determination of nitrate in plant tissue by nitrification of salicylic acid. Communications in Soil Science and Plant Analysis, v.6, p.71-81, 1975. 
COUTO, C.; NOVAIS, R.F.; TEIXEIRA, J.L.; BARROS, N.F.; NEVES, J.C.L. Níveis críticos de zinco no solo e na planta para o crescimento de milho em amostras de solos com diferentes valores do fator capacidade. Revista Brasileira de Ciência do Solo, v.16, p.79-87, 1992.

CSATHÓ, P.; LÁSZTITY, B. Foliar Zn application for eliminating $\mathrm{P}$-induced $\mathrm{Zn}$ deficiency in maize (Zea mays L.). In: CONGRESS OF THE EUROPEAN SOCIETY FOR AGRONOMY, 3., Abano-Padova, 1994. Proceedings. AbanoPadova: European Society for Agronomy, 1994. p.466-467.

EMATER-MG. Resultado do concurso de produtividade de milho 95/96 e panorama do milho. Belo Horizonte, 1996.

FLONERAGAN, J.; WEBB, M.J. Interactions between zinc and other nutrients affecting the growth of plants. In: ROBSON, A.D. (Ed.) Zinc in soils and plants. Dordrecht : Kluwer, 1993. p.119-134.

GALRÃO, E.Z. Métodos de correção da deficiência de zinco para o cultivo do milho num latossolo vermelho-escuro argiloso sob cerrado. Revista Brasileira de Ciência do Solo, v.18, p.229-233, 1994.

GUPTA, U.C.; LIPSETT, J. Molybdenum in soils, plants and animals. Advances in Agronomy, v.34, p.73-115, 1981.

JACKSON, M.L. Soil chemical analysis. Englewood Chiffs: Prentice Hall, 1958. p.183-204: Nitrogen determinations for soil and plant tissue.

JONES JR., J.B.; WOLF, B.; MILLS, H.A. Plant analysis handbook: a practical sampling, preparation, analysis, and interpretation guide. Athens: Micro-Macro, 1991. 213p.

JURKOWSKA, H.; WISNIOWSKA-KIELIAN, B.; ROGOZ, A.; WOJCIECHOWICZ, T. The effect of $\mathrm{N}$-fertilization rate on the levels of mineral components in various plant species: Part II. Microelements. Rolnictwo Z, v.29, p.51-64, 1990.

KILLORN, R.; ZOURARAKIS, D. Nitrogen fertilizer management effects on corn grain yield and nitrogen uptake. Journal of Production Agriculture, v.5, p.142-148, 1992.

LANDRY, J.; DELHAYE, S. The Tryptophan contents of wheat, maize and barley grains as a function of nitrogen content. Journal of Cereal Science, v.18, p.259-266, 1993.

LEMCOFF, J.H.; LOOMIS, R.S. Nitrogen influences on yield determination in maize. Crop Science, v.26, p.1017-1022, 1986.

MALAVOLTA, E.; BOARETTO, A.E., PAULINO, V.T. Micronutrientes - Uma visão geral. In: FERREIRA, M.E.; CRUZ, M.C.P. (Ed.) Micronutrientes na agricultura. Piracicaba: Associação Brasileira para a Pesquisa da Potassa e do Fosfato, 1991. p.1-33.
MARSCHNER, H. Mineral nutrition of higher plant. 2.ed. New York: Academic Press, 1995. 889p.

MELSTED, S.W.; MOTTO, H.L.; PECK, T.R. Critical plant nutrient composition values useful in interpreting plant analysis data. Agronomy Journal, v.61, p.17-20, 1969.

MORAGHAN, J.T.; MASCAGNI JR., H.J. Environmental and soil factors affecting micronutrient deficiencies and toxicities. In: MORTVEDT, J.J.; COX, F.R.; SHUMAN, L.M.; WELCH, R.M. (Ed.) Micronutrients in agriculture. 2.ed. Madison: SSSA, 1991. p.371-425.

RITCHEY, K.D.; COX, F.R.; GALRÃO, E.Z.; YOST, R.S. Disponibilidade de zinco para as culturas do milho, sorgo e soja em Latossolo Vermelho-Escuro Argiloso. Pesquisa Agropecuária Brasileira, v.21, p.215-225, 1986.

SABATA, R.J.; MASON, S.C. Corn hybrid interactions with soil nitrogen level and water regime. Journal of Production Agriculture, v.5, p.137-142, 1992.

TA, C.T.; WEILAND, R.T. Nitrogen partitioning in maize during ear development. Crop Science, v.32, p.443-451, 1992.

TANNER, P.D. The molybdenum requeriments of maize in Zimbabwe. Zimbabwe Agriculture Journal, v.79, p.61-64, 1982.

THIRAPORN, R.; FEIL, B.; STAMP, P. Effect of nitrogen fertilization on grain yield and accumulation of nitrogen, phosphorus and potassium in the grains of tropical maize. Journal of Agronomy \& Crop Science, v.169, p.9-16, 1992.

VIEIRA, C.; NOGUEIRA, A.O.; ARAÚJO, G.A. de A. Adubação nitrogenada e molíbdica na cultura do feijão. Revista de Agricultura, v.67, p.117-124, 1992.

WATT, B.K.; MERRIL, A.L. Handbook of the nutrition contents of foods. New York: Dover Publication, 1975. 190p.

WOLFE, D.W.; HENDERSON, D.W.; HSIAO, T.C.; ALVINO, A. Interactive water and nitrogen effects on senescence of maize: I. Leaf area duration, nitrogen distribution, and yield. Agronomy Journal, v.80, p.859-864, 1988.

ZHANG, F.; MACKENZIE, A.F.; SMITH, D.L. Corn yield and shifts among corn quality constituents following application of different nitrogen fertilizer sources at several times during corn development. Journal of Plant Nutrition, v.16, p.1317-1337, 1993.

ZHANG, F.; MACKENZIE A.F.; SMITH, D.L. Nitrogen fertilizer and protein, lipid, and non-structural carbohydrate concentrations during the course of maize kernel filling. Journal of Agronomy \& Crop Science, v.172, p.171-181, 1994.

Recebido em 26.11 .99 